\title{
Özgün araştırma makalesi \\ Çukurova bölgesinin süpernümerer diş karakteristikleri: çok merkezli retrospektif bir çalışma
}

\author{
Ufuk Tatlı, ${ }^{1 *}$ Burcu Evlice, ${ }^{2}$ Ibrahim Damlar, ${ }^{3}$ \\ Zeki Arslanoğlu, ${ }^{4}$ Ahmet Altan ${ }^{3}$ \\ ${ }^{1}$ Ağız Diş ve Çene Cerrahisi Anabilim Dalı, ${ }^{2}$ Ağız Diş ve Çene \\ Radyolojisi Anabilim Dalı, Çukurova Üniversitesi Diş Hekim- \\ liği Fakültesi, Adana, ${ }^{3}$ Ağız Diş ve Çene Cerrahisi Anabilim \\ Dalı, ${ }^{4}$ Pedodonti Anabilim Dalı, Mustafa Kemal Üniversitesi \\ Diş Hekimliği Fakültesi, Antakya, Türkiye
}

\section{Özet}

AmAÇ: Bu çalışmanın amacı, Çukurova bölgesinde gözlenen süpernümerer dişlere ait demografik özelliklerin incelenmesi ve güncel literatür ile kıyaslanmasıdır.

GEREÇ VE YöNTEM: Bu retrospektif çalışmada, Temmuz 2011Temmuz 2013 tarihleri arasında çeşitli diş problemleri nedeniyle Çukurova Üniversitesi ve Mustafa Kemal Üniversitesi Diş Hekimliği Fakültelerine başvuran 12735 hastanın klinik ve radyografik verileri incelendi. Süpernümerer dişlere ait demografik bulgular, ilişkili komplikasyonlar ve uygulanan tedaviler kayıt edildi. Veriler istatistiksel yöntemlerle analiz edildi; istatistiksel anlamlılık değeri olarak $\mathrm{p}=\mathbf{0 . 0 5}$ kabul edildi.

BULGULAR: Değerlendirilen popülasyon içinde 112 hastada 156 adet süpernümerer diș teșhis edildi. Süpernümerer diş yaygınlığı açısından erkek ve kadınlar arasında istatistiksel olarak anlamlı bir fark tespit edilmedi. Süpernümerer dişlerde anatomik lokalizasyon ile cinsiyet arasında istatistiksel olarak anlamlı bir ilișki tespit edilmedi. Gömülü süpernümerer dişlerin kadın hastalarda istatistiksel olarak anlamlı düzeyde daha fazla olduğu tespit edildi. Süpernümerer dişlerin gömülü olma durumu ile anatomik lokalizasyon arasında istatistiksel olarak anlamlı bir ilișki tespit edilmedi. Hastaların \%51.8'inde ilişkili komplikasyonlar nedeniyle süpernümerer dişler çekildi.

SoNuç: Süpernümerer dişlerin büyük çoğunluğu gömülü olduğundan rutin klinik muayeneler sırasında teşhis edilememekte, ancak komplikasyona neden olduklarında veya radyografik incelemeler sırasında saptanabilmektedirler. Erken tanı ve tedavi ilişkili komplikasyonların önlenmesi açısından önemlidir.

Makale gönderiliş tarihi: 22 Kasım 2013; Yayına kabul tarihi: 08 Aralık 2013 * letetşsim: Ufuk Tattı, Ağız Diş ve Çene Cerrahisi Anabilim Dalı, Çukurova Üniversitesi Diş Hekimliği Fakültesi, 01330, Sarıçam-Balcalı, Adana, Türkiye; e-posta:dr.ufuktatli@gmail.com

\begin{abstract}
Anahtar Kelimeler: Diş, fazla; epidemiyoloji; prevalans; retrospektif çalışmalar

Kaynak Göstermek İçin: Tatı U, Evlice B, Damlar i, Arslanoğlu Z, Altan A. Çukurova bölgesinin süpernümerer diş karakteristikleri: çok merkezli retrospektif bir çalışma. Acta Odontol Turc 2014;31(2):84-8.
\end{abstract}

[Abstract in English is at the end of the manuscript]

\section{Giriș}

Dental arkta belirli bir bölgede olması gerekenden daha fazla sayıdaki dişlere süpernümerer dişler denir. ${ }^{1}$ Süpernümerer dişler daimi dentisyonda daha sık olmakla beraber, hem daimi hem de süt dentisyonda gözlenebilmektedir. ${ }^{2}$ Hiperdonti terimi, süpernümerer diş içeren dentisyonu tanımlamak için kullanılır. ${ }^{2}$ Süpernümerer dişlerin etyolojisi tam olarak bilinmemekle beraber, diş tomurcuğunun tamamen ikiye ayrılması veya normal sayıdaki diş tomurcuğu oluşumundan sonra devam eden dental lamina aktivasyonuna bağlı olarak geliştiği öne sürülen teorilerdir. Bu dişlerin kalıtsal olarak ortaya çıkabildiği de savunulmaktadır. ${ }^{1,3}$

Süpernümerer dişler sıklıkla erkeklerde ve premaksiller bölgede gözlenmektedir. ${ }^{4-7}$ Literatürde süpernümerer dişler lokalizasyonlarına göre mesiodens (iki ön kesici arasında), parapremolar (küçük azı dişler arasında) paramolar (büyük azı dişler arasında) ve distomolar (üçüncü büyük azı distalinde) olarak sınıflandırmıştır. ${ }^{2,8}$

Süpernümerer dişler sürme bozukluğu, sürme gecikmesi, dişlerde yer değişiklikleri, yer darlığı, primordial veya foliküler kist oluşumları, ilgili bölgede ağrı ve şişlik, komşu dişlerde patolojik kök rezorpsiyonları gibi çeşitli problemlere sebep olabilmektedir. ${ }^{5-7}$

Çok sayıda süpernümerer dişe aynı olguda rastlanması çok nadirdir ve genellikle sistemik bir rahatsızlık veya sendromla birlikte görülür. Süpernümerer dişlerin en sık görüldüğü sendromlar Gardner Sendromu, EhlerDanlos Sendromu, Kleidokranial Disostozis, NanceHoran Sendromu, Fabry-Anderson Sendromu, Trikorinofalangeal Sendrom ve dudak-damak yarıkları- 
dır. ${ }^{2,3,5,9}$ Non-sendromik multiple süpernümerer diş yaygınlığı \%1'den azdır. ${ }^{3}$

Süpernümerer bir dişin hipodonti ile birlikte aynı çenede görülmesi Gibson tarafından hipo-hiperdonti olarak tanımlanmıştır ve literatürde az sayıda vaka rapor edilmiştir. ${ }^{10-12}$

Bu çalışmada, Türkiye'nin güneyindeki Çukurova bölgesinde gözlenen süpernümerer dişlere ait karakteristik demografik verilerin incelenmesi ve güncel literatür ile kıyaslanması amaçlanmıştır.

\section{Gereç Ve Yöntem}

Bu çok merkezli retrospektif çalışmada, Temmuz 2011Temmuz 2013 tarihleri arasında çeşitli diş problemleri nedeniyle Çukurova Üniversitesi Diş Hekimliği Fakültesi ve Mustafa Kemal Üniversitesi Diş Hekimliği Fakültesine başvuran 12735 hastanın klinik, radyografik ve demografik verileri hasta dosyaları üzerinden geçmişe dönük olarak analiz edildi. Tüm hastalardan rutin muayenenin bir parçası olarak aydınlatılmış onam alındı. Radyografik kayıtlar aracılığıyla süpernümerer dişe sahip olan hastalara ait; yaş, cinsiyet, süpernümerer diş sayısı, dişin saptandığı anatomik lokalizasyon, erüpsiyon durumu, süpernümerer dişlerin neden oldukları komplikasyonlar ve uygulanan tedaviler kayıt edildi. Süpernümerer dişlerin neden oldukları komplikasyonlar: daimi diş erüpsiyonunu engelleme, dişlerde çapraşıklık ve odontojenik kist oluşumu olarak kaydedildi. Herhangi bir komplikasyona neden olmayan dişler asemptomatik olarak sınıflandırıldı.

Verilerin istatistiksel analizinde MedCalc 12.7.5 paket programı (MedCalc, Mariakerke, Belçika) kullanıldı. Verilerin analizinde tanımlayıcı istatistik ve ki-kare testi kullanıldı. P değeri 0.05 'ten küçük olduğunda değişkenler arasındaki fark istatistiksel olarak anlamlı kabul edildi.

\section{BULGULAR}

12735 hastadan 112'sinde toplam 156 adet süpernümerer diş teşhis edildi. Değerlendirilen popülasyon içinde süpernümerer dişi bulunan hasta yaygınlığı $\% 0.88$ olarak bulundu. Süpernümerer diş yaygınlığı açısından erkek ve kadınlar arasında istatistiksel olarak anlamlı bir fark tespit edilmedi ( $p=0.271$; Tablo 1$)$. Süpernümerer diş tespit edilen hastaların yaş ortalaması 19.5 \pm 10.2 idi (median: 18; yaş aralığı: 5-58). Hastalardan 57'si (\%50.9) erkekti, erkek-kadın oranı 1.04:1 olarak bulundu. Süpernümerer dişlerin \%69.2'si üst çenede gözlendi ve üst çene-alt çene oranı 2.2:1 olarak bulundu. Süpernümerer dişlerde anatomik lokalizasyon ile cinsiyet arasında istatistiksel olarak anlamlı bir ilişki tespit edilmedi ( $p=0.565$; Tablo 2). Süpernümerer dişlerin 115 tanesi (\%73.7) gömülü idi ve gömülü-sürmüş oranı 2.8:1 olarak bulundu. Süpernümerer dişlerin gömülü olma durumu ile cinsiyet arasındaki ilişki değer-

Tablo 1. Çalışma popülasyonu içindeki süpernümerer diş yaygınlığı

\begin{tabular}{lccc}
\hline Cinsiyet & Popülasyon & Süpernümerer diş görülen hasta sayısı & Yaygınlık (\%) \\
\hline Erkek & 5769 & 57 & 0.99 \\
Kadın & 6966 & 55 & 0.79 \\
Toplam & 12735 & 112 & 0.88 \\
\hline
\end{tabular}

$\mathrm{P}=0.271$ (Pearson ki-kare testi); SD: süpernümerer diş

Tablo 2. Süpernümerer dişlerin cinsiyet ile lokalizasyon ilişkisinin değerlendirilmesi; süpernümerer diş sayısı (\%)

\begin{tabular}{lccc}
\hline & Üst çene (\%) & Alt çene (\%) & Toplam (\%) \\
\hline Erkek & $52(72.2)$ & $20(27.8)$ & $72(46.2)$ \\
Kadın & $56(66.7)$ & $28(33.3)$ & $84(53.8)$ \\
Toplam & $108(69.2)$ & $48(30.8)$ & $156(100)$ \\
\hline
\end{tabular}

$\mathrm{P}=0.565$ (Pearson ki-kare testi)

Tablo 3. Süpernümerer dişlerin gömülülük durumu ile cinsiyet ilişkisinin değerlendirilmesi; süpernümerer diş sayısı (\%)

\begin{tabular}{lccc}
\hline & Gömülü (\%) & Sürmüş (\%) & Toplam (\%) \\
\hline Erkek & $46(63.9)$ & $26(36.1)$ & $72(46.2)$ \\
Kadın & $69(82.1)$ & $15(17.9)$ & $84(53.8)$ \\
Toplam & $115(73.7)$ & $41(26.3)$ & $156(100)$ \\
\hline
\end{tabular}

$\mathrm{P}=0.016$ (Pearson ki-kare testi) 
Tablo 4. Süpernümerer dişlerin gömülülük durumu ile lokalizasyon ilişkisinin değerlendirilmesi; süpernümerer diş sayısı (\%)

\begin{tabular}{lccc}
\hline & Gömülü (\%) & Sürmüş (\%) & Toplam (\%) \\
\hline Maksilla & $79(73.1)$ & $29(24.9)$ & $108(69.2)$ \\
Mandibula & $36(75)$ & $12(25)$ & $48(30.8)$ \\
Toplam & $115(73.7)$ & $41(26.3)$ & $156(100)$ \\
\hline
\end{tabular}

$\mathrm{P}=0.963$ (Pearson ki-kare testi)

lendirildiğinde, gömülü süpernümerer dişlerin kadın hastalarda istatistiksel olarak anlamlı düzeyde daha fazla olduğu tespit edildi ( $p=0.016$; Tablo 3). Süpernümerer dişlerin gömülü olma durumu ile anatomik lokalizasyon arasında istatistiksel olarak anlamlı bir ilişki tespit edilmedi ( $p=0.963$; Tablo 4). Süpernümerer dişlerin anatomik lokalizasyonlara göre dağılımı Şekil 1'de yüzde olarak belirtildi. Süpernümerer diş teşhis edilen hastaIarın dişlenme durumuna göre dağılımı Tablo 5’te belirtildi.

Değerlendirilen popülasyon içerisinde 27 hastada (\%0.21) çok sayıda non-sendromik süpernümerer diş saptandı. Hastaların 21'inde 2 adet, 1'inde 3 adet, 4'ünde 4 adet, 1 'inde de 10 adet süpernümerer diş gözlendi. Süpernümerer diş sayısı ile cinsiyet arasında istatistiksel olarak anlamlı bir ilişki bulunmadığı tespit edildi (Tablo 6; $p=0.196$ ).

Süpernümerer diş teşhis edilen hastalardan 54'ünde (\%48.2) dişlerin asemptomatik olması nedeniyle rutin aralıklarla klinik ve radyolojik olarak takip edilmesi planlandı. Kalan 58 hastada ise süpernümerer dişlerle ilişkili komplikasyonlar nedeniyle dişlerin çekimi planlandı. Söz konusu komplikasyonların dağılımı Tablo 7'de belirtildi.

\section{TARTIŞMA}

Daimi dentisyonda rapor edilen süpernümerer diş yaygınlığı \%1-3.5 arasındadır. ${ }^{13,14}$ Çelikoğlu ve ark. ${ }^{4} 2010$ yılında Doğu Anadolu bölgesinde 3491 kişilik Türk popülasyonunda yaptıkları çalışmalarında süpernümerer diş yaygınlığını \%1.2 olarak rapor etmişlerdir. Bizim çaısşmamızda süpernümerer diş yaygınlığı \%0.88 olarak bulunmuştur ve bu değerden düşüktür. Literatürde genellikle süpernümerer dişlerin erkeklerde görülme yüzdesi daha fazla olarak rapor edilmiştir.4,15-17 Bizim çalışmamızda da istatistiksel olarak anlamlı olmamakla

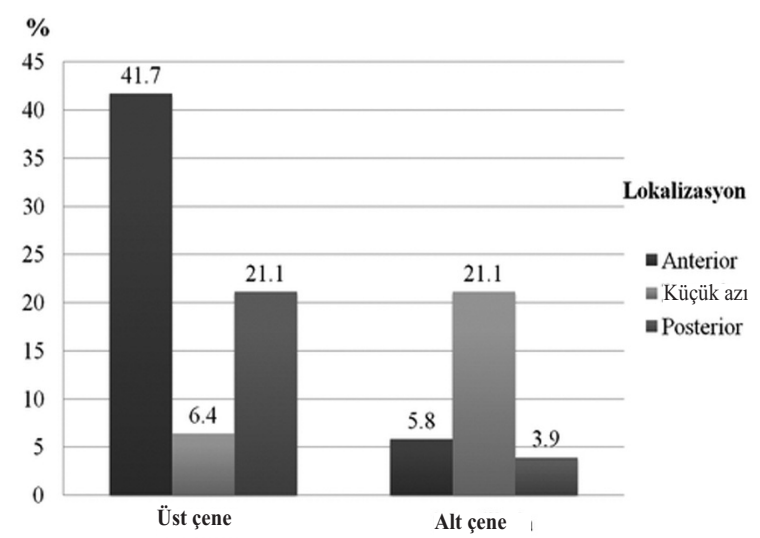

Şekil 1. Süpernümerer diş tespit edilen 112 hastada (156 diş) süpernümerer dişlerin anatomik lokalizasyonlara göre dağıımı

Tablo 5. Süpernümerer dişi bulunan hastaların dişlenme (dentisyon) durumuna göre dağııımı; hasta sayısı (\%)

\begin{tabular}{lc}
\hline Süt & $4(3.6)$ \\
Karışık & $38(33.9)$ \\
Daimi & $70(62.5)$ \\
Toplam & $112(100)$ \\
\hline
\end{tabular}

beraber erkek hastalarda süpernümerer diş yaygınlığı daha fazla bulundu (\%0.99).

Süpernümerer diş tespit edilen hastaların hepsi, bu dişlerin ilk olarak bu merkezde tespit edildiğini bildirmiştir. Süpernümerer dişlerin dentisyon durumuna göre dağılımı, oluşum zamanlarının yanısıra, teşhis edilme zamanlarını da göstermektedir. Bu sebeple söz konusu yüzdeler, bireylerin kapsamlı bir dental muayeneden geçtikleri ilk zaman diliminin göstergesi olarak da değerlendirilebilir. Dolayısıyla Çukurova bölgesindeki has-

Tablo 6. Hastaların süpernümerer diş sayısına göre dağılımı ve cinsiyet ilişkisinin değerlendirilmesi; hasta sayısı (\%)

\begin{tabular}{lcccc}
\hline & 1 Süpernümerer diş (\%) & 2 Süpernümerer diş (\%) & 23 Süpernümerer diş (\%) & Toplam (\%) \\
\hline Erkek & $47(82.4)$ & $7(12.3)$ & $3(5.3)$ & $57(50.9)$ \\
Kadın & $38(69.1)$ & $14(25.4)$ & $3(5.5)$ & $55(49.1)$ \\
Toplam & $85(75.9)$ & $21(18.7)$ & $6(5.4)$ & $112(100)$ \\
\hline
\end{tabular}

$\mathrm{P}=0.196$ (Pearson ki-kare testi); SD: süpernümerer diş 
Tablo 7. Süpernümerer diş teşhis edilen 112 hastada gözlenen komplikasyonların dağıımı; hasta sayısı (\%)

\begin{tabular}{lc}
\hline Asemptomatik & $54(48.2)$ \\
Daimi diş erüpsiyonunu engelleme & $40(35.7)$ \\
Dişlerde çapraşıklık & $14(12.5)$ \\
Odontojenik kist oluşumu & $4(3.6)$ \\
Toplam & $112(100)$ \\
\hline
\end{tabular}

taların \%62.5'inin kapsamlı bir klinik ve radyografik muayeneden ilk olarak daimi dişlenme döneminde geçtiği yorumlanabilir. Süpernümerer dişler ne kadar erken aşamada teşhis edilirse, ilişkili komplikasyonlar da o kadar azalacağından, çalışmanın sonuçları hastaların bu konuda bilinçlendirilmesi gerektiğini ortaya çıkarmaktadır.

Fernandez Montenegro ve ark. ${ }^{18}$ süpernümerer dişe sahip olan hastaların \%76-86'sında bir adet fazla diş, \%12-23'ünde iki adet fazla diş, \%1'inde ise üç veya daha fazla sayıda fazla diş saptandığını rapor etmişlerdir. Bizim çalışmamızda da literatürle uyumlu olarak süpernümerer diş bulunan olguların \%75.9'unda bir adet, $\% 18.7$ 'sinde ise iki adet süpernümerer diş tespit edildi. Çalışmamızda üç veya daha fazla sayıda süpernümerer diş bulunan hastaların oranı (\%5.4) literatürden yüksek bulunmuştur. Bu durum, ırksal farklılıktan kaynaklanmış olabilir.

Değerlendirilen 112 olgudan 54'ünde (\%48.2) süpernümerer dişlerin takip edilmesi planlanmıştır. Benzer şekilde; Ertaş ve ark. ${ }^{15}$ meziodens yaygınlığını değerlendirdikleri çalışmalarında, süpernümerer dişlerin \%41.9'unun asemptomatik olduğunu rapor etmişlerdir. Çevre bölgede sürme anomalilerine ve patolojik oluşumlara neden olmayan gömülü veya süpernümerer dişlerin çekilmemesi ve böylece gelecekteki olası diş kayıplarında bu dişlerin ilgili bölgelere transplante edilebilecek rezervuar dişler olarak değerlendirilmesi düşünülebilir. ${ }^{19}$

Çalışmamızda, süpernümerer dişler en sık üst çeneön bölgede, takiben üst çene-arka ve alt çene-küçük azı bölgelerinde, sonrasında üst çene-küçük azı, alt çeneön bölge ve en az olarak alt-çene arka bölgede gözlenmiştir (Şekil 1). Süpernümerer dişler rutin radyografik muayeneler sırasında tesadüfen fark edilebildiği gibi, sıklıkla komşu dişlerde sürme gecikmesi veya yer değişikliği oluşturmaları sonucu fark edilirler. ${ }^{20}$ Literatürde süpernümerer dişlerin komşu dişlerde kron ve kök rezorpsiyonuna neden olabileceği rapor edilmiştir. ${ }^{20,21}$ ÇaIışmamızda, Ertaş ve arkadaşlarının ${ }^{15}$ çalışmasıyla uyumlu olarak, komşu dişlerde kök rezorpsiyonu gözlenmedi. Çalışmamızda süpernümerer dişlerle ilişkili en sık gözlenen komplikasyon, daimi diş erüpsiyonunun engellenmesidir. Erken aşamada fark edilemeyen va- kalarda, ortodontik ve cerrahi tedavi intiyacı oluşmaktadır. Üst çenede gözlenen süpernümerer dişlerin \%60.2'si ön bölgede, alt çenede gözlenen süpernümerer dişlerin \%68.7'si küçük azı bölgesinde gözlenmektedir. Dolayısıyla sıklıkla gözlendikleri bu bölgelerde ilgili dişlerin sürme yaşından önce yapılacak radyografik muayeneler ile erken aşamada teşhis edilebilirler.

Hiperdontinin genetik bir temele dayandığını ve ailesel geçiş gösterdiğini öne süren birçok çalışma mevcuttur. ${ }^{22-24}$ Khambete ve Kumar, ${ }^{23}$ baba, oğul ve torunlar olmak üzere 3 nesilde süpernümerer diş tespit ettiklerini rapor etmişlerdir. Bu sebeple, akraba evliliklerinin sık oranda görüldüğü ülkemizde, özellikle yakın akrabalarında süpernümerer diş bulunan bireylerin titizlikle radyografik muayenelerden geçmeleri süpernümerer dişlerin erken teşhisini sağlayabilir.

\section{SonUç}

Çukurova bölgesine ait süpernümerer diş verileri birtakım farklılıklar göstermekle beraber genel hatlarıyla literatürle uyumludur. Süpernümerer dişlerin büyük çoğunluğu gömülü olduğundan rutin klinik muayeneler sırasında teşhis edilememekte, ancak komplikasyona neden olduklarında veya radyografik incelemeler sırasında saptanabilmektedirler. Teşhisin gecikmesi, daha kapsamlı tedaviler gerektireceğinden erken tanı ve tedavi ilişkili komplikasyonların önlenmesi açısından önemlidir.

Çıkar çatışması: Yazarlar bu çalışmayla ilgili herhangi bir çıkar çatışmalarının bulunmadığını bildirmişlerdir.

\section{KAYNAKLAR}

1. Shafer WG, Hine MK, Levy BM. A textbook of oral pathology. 4th ed. Philadelphia: WB Saunders; 1983.

2. Anthonappa RP, Omer RS, King NM. Characteristics of 283 supernumerary teeth in southern Chinese children. Oral Surg Oral Med Oral Pathol Oral Radiol Endod 2008;105:e48-54.

3. Anthonappa RP, King NM, Rabie AB. Aetiology of supernumerary teeth: a literature review. Eur Arch Paediatr Dent 2013;14:279-88.

4. Celikoglu M, Kamak H, Oktay $H$. Prevalence and characteristics of supernumerary teeth in a non-syndrome Turkish population: associated pathologies and proposed treatment. Med Oral Patol Oral Cir Bucal 2010;15:e575-8.

5. Altuğ HA, Altuğ H, Sarı E, Şençimen M, Altun C. Süt ve daimi dentisyonda süpernümere dişlerin teşhisi, cerrahi ve ortodontik olarak tedavileri. GÜ Diş Hek Fak Derg 2010;27:77-82.

6. Tuna EB, Kurklu E, Gencay K, Ak G. Clinical and radiological evaluation of inverse impaction of supernumerary teeth. Med Oral Patol Oral Cir Bucal 2013;18:e613-8.

7. De Oliveira Gomes C, Drummond SN, Jham BC, Abdo EN, Mesquita RA. A survey of 460 supernumerary teeth in Brazilian children and adolescents. Int J Paediatr Dent 2008;18:98-106.

8. Garvey MT, Barry HJ, Blake M. Supernumerary teeth--an overview of classification, diagnosis and management. J Can Dent Assoc 1999;65:612-6. 
9. Açikgöz A, Açikgöz G, Tunga U, Otan F. Characteristics and prevalence of non-syndrome multiple supernumerary teeth: a retrospective study. Dentomaxillofac Radiol 2006;35:185-90.

10. Gibson AC. Concomitant hypo-hyperodontia. $\mathrm{Br} \mathrm{J}$ Orthod 1979;6:101-5.

11. Mallineni SK, Jayaraman J, Yiu CK, King NM. Concomitant occurrence of hypohyperdontia in a patient with Marfan syndrome: a review of the literature and report of a case. J Investig Clin Dent 2012;3:253-7.

12. Manjunatha BS, Nagarajappa D, Singh SK. Concomitant hypohyperdontia with dens invaginatus. Indian J Dent Res 2011;22:468-71.

13. Kumar DK, Gopal KS. An epidemiological study on supernumerary teeth: a survey on 5,000 people. J Clin Diagn Res 2013;7:1504-7.

14. Marsillac Mde W, Andrade MR, Fonseca Rde O, Marcal SL, Santos VL. Dental anomalies in panoramic radiographs of pediatric patients. Gen Dent 2013;61:e29-33.

15. Ertaş ET, Şişman $Y$, Yırcalı MA. Bir grup Türk popülasyonunda görülen meziodenslerin sıklığı, özellikleri ve meydana getirdikleri komplikasyonlar. Cumhuriyet Dent J 2013;16:267-72.

16. Harris EF, Clark LL. An epidemiological study of hyperdontia in American blacks and whites. Angle Orthod 2008;78:460-5.

17. Hyun HK, Lee SJ, Ahn BD, Lee ZH, Heo MS, Seo BM, et al. Nonsyndromic multiple mandibular supernumerary premolars. J Oral Maxillofac Surg 2008;66:1366-9.

18. Fernández Montenegro $P$, Valmaseda Castellón E, Berini Aytés L, Gay Escoda C. Retrospective study of 145 supernumerary teeth. Med Oral Patol Oral Cir Bucal 2006;11:E339-44.

19. Tatli U, Kürkçü M, Cam OY, Büyükyilmaz T. Autotransplantation of impacted teeth: a report of 3 cases and review of the literature. Quintessence Int 2009;40:589-95.

20. Dayı E, Orbak R. Meziodensler ve tedavi yaklaşımları. Atatürk Üniv Diş Hek Fak Derg 1999;9:91-5.

21. Gündüz K, Celenk $P$, Zengin $Z$, Sümer $P$. Mesiodens: a radiographic study in children. J Oral Sci 2008;50:287-91.

22. Inchingolo $F$, Tatullo $M$, Abenavoli FM, Marrelli M, Inchingolo AD, Gentile M, et al. Non-syndromic multiple supernumerary teeth in a family unit with a normal karyotype: case report. Int J Med Sci 2010;7:378-84.

23. Khambete N, Kumar R. Genetics and presence of non-syndromic supernumerary teeth: A mystery case report and review of literature. Contemp Clin Dent 2012;3:499-502.

24. Klein OD, Oberoi S, Huysseune A, Hovorakova M, Peterka M, Peterkova R. Developmental disorders of the dentition: an update. Am J Med Genet C Semin Med Genet 2013;163:318-32.

\section{Supernumerary tooth characteristics of Çukurova region: a multicenter retrospective study}

Abstract

OBJECTIVE: The aim of this study was to evaluate the demographic characteristics of supernumerary teeth in Çukurova region and to compare the results with the current literature.

MATERIALS AND METHOD: In the present retrospective study, clinical and radiological data of the 12735 patients admitted to the dental faculties of Çukurova and Mustafa Kemal Universities between July 2011 and July 2013 were evaluated. Demographic characteristics of the supernumerary teeth, related complications and applied treatment were recorded. Data was analyzed statistically and the statistical significance was set to $\mathrm{p}=0.05$.

RESULTS: In the study population, 156 supernumerary teeth were diagnosed in 112 patients. In terms of supernumerary tooth prevalence, no statistically significant difference was found between male and female patients. No statistically significant association between anatomic localization and gender was observed. The impacted supernumerary teeth were significantly more frequent in female patients. No statistically significant association was observed between the impacted supernumerary tooth and the anatomic localization. In $51.8 \%$ of the patients, the supernumerary tooth was extracted due to related complications.

ConcLusion: Because the majority of the supernumerary teeth are impacted, they cannot be diagnosed during routine clinical examination. However they can only be detected during radiological examination or when they cause complications. Early diagnosis and treatment are crucial to prevent the related complications.

KEYWORDS: Epidemiology; prevalence; retrospective studies; tooth, supernumerary 